\title{
Overtone spectra of porphyrins and its substituted forms: an algebraic approach
}

\author{
Srinivasa Rao Karumuri ${ }^{1 *}$, Ambati Siva Rama Prasad ${ }^{2}$, Nirmal Kumar Sarkar ${ }^{3}$, Joydeep \\ Choudhury ${ }^{4}$, Ramendu Bhattacharjee ${ }^{4}$
}

\author{
${ }^{1}$ Faculty of Sciences \& Humanities, Sri Viveka Institute of Technology (SVIT), Vijayawada, India; *Corresponding Author: \\ drsrkarumuri@rediffmail.com \\ ${ }^{2}$ Faculty, Department of Mathematics, P.B. Siddhartha College of Arts \& Sciences, Vijayawada, India \\ ${ }^{3}$ Faculty, Department of Physics, Karimganj College, Karimganj, India \\ ${ }^{4}$ Faculty, Department of Physics, Assam (A Central) University, Silchar, India
}

Received 8 June 2010; revised 13 July 2010; accepted 18 July 2010.

\begin{abstract}
We introduce an algebraic model to vibrations of polyatomic Bio-molecules and present, as an example, the vibrational analysis of $\mathrm{C}_{\mathrm{m}}-\mathrm{H}, \mathrm{C}_{\mathrm{m}}-\mathrm{C}$, $C_{m}-D, C_{b}-C_{b}$, pyrrol breathing and $C_{b}-C$, stretching modes of Metalloporphyrins and its substituted forms. The excited energy levels of $C_{b}-C$, pyrrol breathing stretching modes of $\mathrm{Ni}(\mathrm{OEP})$ and $\mathrm{Ni}(\mathrm{OEP})-\mathrm{d}_{4}$ are calculated by using $\mathrm{U}(2)$ algebraic mode Hamiltonian. The higher excited energy levels of $C_{m}-H, C_{m}-C, C_{m}-D$ and $C_{b}-C_{b}$ vibrational modes of Porphyrin and its substituted forms are predicted upto second overtone. It shows that the energy levels are clustering at the higher overtones. The results obtained by this method are accuracy with experimental data.
\end{abstract}

Keywords: Algebraic Model; Vibrational Spectra; Energy Levels; Metalloporphyrins

\section{INTRODUCTION}

Recently measurement of highly-excited overtone-combination spectra of molecules have renewed in a theoretical description and understanding of the observed spectral properties. Two approaches have been mostly used so far in an analysis of experimental data: 1) the familiar Dunham like expansion of energy levels in terms of rotations-vibrations quantum numbers and 2) the solution of Schrodinger equation with potentials obtained either by appropriately modifying ab-initio calculations or by more phenomenological methods. In this article, we begin a systematic analysis of overtonecombination spectra of molecules in terms of novel ap- proach: 3) Vibron model [1-4]. This model is a formulation of the molecular spectral problem in terms of elements of Lie algebra and it contains the same physical information of the Dunham and potential approach. However, by making use of the powerful methods of group theory, one is able to obtain the desired results in a much faster and straightforward way.

In recent years, these polyatomic bio-molecules (i.e Metalloporphyrins) have numerous importances in the field of Chemical Physics. In case of polyatomic biomolecules the parameters play major role in the Vibron model. Of course, we have explicitly described with few parameters, the vibrational bands of the triatomic linear molecules HCN, OCS, HCP [5-7] and tetratomic molecules HCCF, HCCD by using an algebraic approach [8]. We have also reported the vibrational bands of tetrahedral molecules $\mathrm{CCl}_{4}, \mathrm{SnBr}_{4}$ and Propadiene [9-11] and polyatomic bio-molecules like Nickel Octaethyl porphyrin, Nickel porphyrin molecules using U (2) Vibron model respectively [12-18]. The advantage of the algebraic approach, as compared to that of Dunham or phonological potential models, is that typically it requires few parameters to obtain the same level of accuracy. It also provides a simultaneous description of bending and stretching modes [19-25].

In Section 2, review the theory of algebraic model to polyatomic molecules is described. In Section 3, the calculation procedure of Vibron number and the fitting algebraic parameters corresponding to various Porphyrins and its substitute form molecule results are discussed. Finally, the conclusions are presented in Section 4.

\section{THEORY: AN ALGEBRAIC APPROACH}

A complete description of the theoretical foundations 
needed to formulate the algebraic model for a vibrating molecule. We apply the one-dimensional algebraic model, consisting of a formal replacement of the interatomic, bond coordinates with unitary algebras. To say it in different words, the second-quantization picture suited to describe anharmonic vibrational modes, is specialized through an extended use of Lie group theory and dynamical symmetries. By means of this formalism, one can attain algebraic expressions for eigenvalues and eigenvectors of even complex Hamiltonian operators, including intermode coupling terms as well expectation values of any operator of interest (such as electric dipole and quadrupole interactions). Algebraic model are not ab-initio methods, as the Hamiltonian operator depends on a certain number of a priori undetermined parameters. As a consequence, algebraic techniques can be more convincingly compared with semi-empirical approaches making use of expansions over power and products of vibrational quantum numbers, such as a Dunham-like series. However, two noticeable advantages of algebraic expansions over conventional ones are that 1) algebraic modes lead to a (local) Hamiltonian formulation of the physical problem at issue(thus permitting a direct calculation of eigenvectors in this same local basis) and 2) algebraic expansions are intrinsically anharmonic at their zero-order approximation. This fact allows one to reduce drastically the number of arbitrary parameters in comparison to harmonic series, especially when facing medium-or large- size molecules. However, it should also be noticed that, as a possible drawback of purely local Hamiltonian formulations (either algebraic or not) compared with traditional perturbative approaches, the actual eigenvectors of the physical system. Yet, for very local situations, the aforementioned disadvantage is not a serious one. A further point of import here is found in the ease of accounting for proper symmetry adaptation of vibrational wave functions. This can be a great help in the systematic study of highly excited overtones of not-so-small molecules, such as the present one. Last but not least, the local mode picture of a molecule is enhanced from the very beginning within the algebraic framework. This is an aspect perfectly lined up with the current tendencies of privileging local over normal mode pictures in the description of most topical situations.

\subsection{Hamiltonian Operators}

We address here the explicit problem of the construction of the vibrational Hamiltonian operator for the Metalloporphyrin molecules. According to the general algebraic description for one-dimensional degrees of freedom, a dynamically-symmetric Hamiltonian operator for n-interacting (not necessarily equivalent) oscillators can be written as

$$
H=E_{0}+\sum_{i=1}^{n} A_{i} C_{i}+\sum_{i<j}^{n} A_{i j} C_{i j}+\sum_{i\langle j}^{n} \lambda_{i j} M_{i j}
$$

In this expresssion, one finds three different classes of effective contributions. The first one, $\sum_{i=1}^{n} A_{i} C_{i}$ is devoted to the description of $\mathrm{n}$ independent, anharmonic sequences of vibrational levels (associted wih $n$ independent, local oscillator) in terms of the operators $C_{i}$. The second one, $\sum_{i<j}^{n} A_{i j} C_{i j}$ leads to cross-anharmonicities between pairs of distinct local oscillators in terms of the operators $C_{i j}$. The third one, $\sum_{i<j}^{n} \lambda_{i j} M_{i j}$, describes anharmonic, non-diagonal interactions involving pairs of local oscillators in terms of the operators $M_{i j}$. The $C_{i}, C_{i j}$ operators are invariant (Casimir) operators of certain Lie algebras, whilst the $M_{i j}$ are invariant (Majorana) operators associated with coupling schemes involving algebras naturally arising from a systematic study of the algebraic formulation of the one-dimensional model for $\mathrm{n}$ interacting oscillators. We work in the local (uncoupled oscillaators) vibrational basis written as

$$
|v\rangle \equiv\left|v_{1} v_{2} v_{3} \ldots \ldots v_{n}\right\rangle
$$

In which the aforementioned operators have the following matrix elements

$$
\begin{gathered}
\left\langle v\left|C_{i}\right| v\right\rangle=-4 v_{i}\left(N_{i}-v_{i}\right) \\
\left\langle v\left|C_{i j}\right| v\right\rangle=-4\left(v_{i}+v_{i}\right)\left(N_{i}+N_{j}-v_{i}-v_{j}\right) \\
\left\langle v^{!}\left|M_{i j}\right| v\right\rangle=\left(v_{i} N_{i}+v_{j} N_{j}-2 v_{i} v_{j}\right) \delta_{v_{i}^{\prime} v_{i}} \delta_{v_{j}^{\prime} v_{j}} \\
\left\langle v^{\prime}\left|M_{i j}\right| v\right\rangle=-\left[\left(v_{i}+1\right)\left(N_{i}-v_{i}\right) v_{j}\left(N_{j}-v_{j}+1\right)\right]^{1 / 2} \delta_{v_{i}^{\prime}-1 v_{i}} \delta_{v_{j}^{\prime}+1 v_{j}} \\
\left\langle v^{\prime}\left|M_{i j}\right| v\right\rangle=-\left[\left(v_{j}+1\right)\left(N_{j}-v_{j}\right) v_{i}\left(N_{i}-v_{i}+1\right)\right]^{1 / 2} \delta_{v_{i}^{\prime}+1 v_{i}} \delta_{v_{j}^{\prime}-1 v_{j}}
\end{gathered}
$$

We note, in particular, that the expressions above depend on the numbers $N_{i}$ (Vibron numbers). Such numbers have to be seen as predetermined parameters of well-defined physical meaning, as they relate to the intrinsic anharmonicity of a single, uncoupled oscillator through the simple relation. We report in Table $4 \&$ Table 5 the values of the Vibron numbers used in the present study.

The general Hamiltonian operator (1) can be adapted to describe the internal, vibrational degrees of freedom of any polyatomic molecule in two distinct steps. First, we associate three mutually perpendicular one-dimensional anharmonic oscillators to each atom. This procedure eventually leads to a redundant picture of the whole molecule, as it will include spurious (i.e translational/rotational) degrees of freedom. However, it is possible to remove easily such spurious modes through 
different techniques. One is thus left with a Hamiltonian operator dealing only with true vibrations. Such modes are given in terms of coupled oscillators in the local basis (3). The coupling is induced by the Majorana operators. A sensible use of these operators is such that the correct symmetries of vibrational wave functions are properly taken into account. As a second step, the algebraic parameters $A_{i}, A_{i j}, \lambda_{i j}$ of Eq.1 need to be calibrated to reproduce the observed spectrum. Let us clarify the actual meaning of these two steps by considering explicitly the $C_{m}-H / C_{m}-D / C_{m}-N$ stretches manifold of the Nickel Metalloporphyrin molecule.

We limit ourselves to in-plane $\mathrm{C}_{\mathrm{m}}-\mathrm{H} / \mathrm{C}_{\mathrm{m}}-\mathrm{D} / \mathrm{C}_{\mathrm{m}}-\mathrm{N}$ stretching motions i.e., without including possible coupling terms with ring deformation. So, we can write for these remaining four degrees of freedom the Hamiltonian operator,

$$
H_{C H}=\sum_{i=1}^{4} A_{i} C_{i}+\sum_{i<j}^{4} A_{i j}^{!} C_{i j}+\sum_{i<j}^{4} \lambda_{i j} M_{i j}
$$

The algebraic theory of polyatomic molecules consists in the separate quantization of rotations and vibrations in terms of vector coordinates $r_{1}, r_{2}, r_{3}, \ldots \ldots$ quantized through the algebra

$$
G \equiv U_{1}(2) \otimes U_{2}(2) \otimes U_{3}(2) \otimes
$$

For the stretching vibrations of polyatomic molecules correspond to the quantization of anharmonic Morse oscillators, with classical Hamiltonian

$$
H\left(p_{s}, s\right)=p_{s}^{2} / 2 \mu+\mathrm{D}[1-\exp (-\beta s)]^{2}
$$

For each oscillator i, states are characterized by representations of

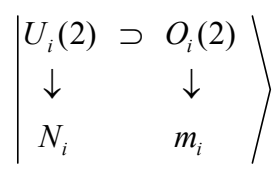

With $m_{i}=N_{i}, N_{i}-2, \ldots \ldots, 1$ or 0 ( $N_{i}$ - odd or even). The Morse Hamiltonian (2) can be written, in the algebraic approach, simply as

$$
H_{i}=\varepsilon_{0 i}+A_{i} C_{i},
$$

where $C_{i}$ is the invariant operator of $O_{i}(2)$, with eigen values

$$
\varepsilon_{\mathrm{i}}=\varepsilon_{0 \mathrm{i}}+\mathrm{A}_{\mathrm{i}}\left(\mathrm{m}_{\mathrm{i}}^{2}-\mathrm{N}_{\mathrm{i}}^{2}\right) .
$$

Introducing the vibrational quantum number $v_{i}=$ $\left(\mathrm{N}_{\mathrm{i}}-\mathrm{m}_{\mathrm{i}}\right) / 2,[26]$ one has

$$
\varepsilon_{i}=\varepsilon_{0 i}-4 A_{i}\left(N_{i} v_{i}-v_{i}^{2}\right) .
$$

For non-interacting oscillators the total Hamiltonian is

$$
\text { With eigenvalues } \mathrm{H}=\sum_{i} H_{i} \text {, }
$$

$$
E=\sum_{i} \varepsilon_{i}=E_{0}-\sum_{i} 4 A_{i}\left(N_{i} v_{i}-v_{i}^{2}\right) .
$$

\subsection{Hamiltonian for Stretching Vibrations}

The interaction potential can be written as

$$
V\left(s_{i}, s_{j}\right)=k_{i j}{ }^{\prime}\left[1-\exp \left(-\alpha_{i} s_{i}\right)\right]\left[1-\exp \left(-\alpha_{j} s_{j}\right)\right],
$$

which reduces to the usual harmonic force field when the displacements are small

$$
V\left(s_{i}, s_{j}\right) \approx k_{i j} s_{i} s_{j} .
$$

Interaction of the type Eq.7 can be taken into account in the algebraic approach by introducing two terms [26]. One of these terms is the Casimir operator, $C_{i j}$, of the combined $O_{i}(2) \otimes O_{j}(2)$ algebra. The matrix elements of this operator in the basis Eq.3 are given by

$$
\begin{gathered}
\left\langle N_{i}, v_{i} ; N_{j}, v_{j}\left|C_{i j}\right| N_{i}, v_{i} ; N_{j}, v_{j}\right\rangle=4\left[\left(v_{i}+v_{j}\right)^{2}-\right. \\
\left.\left(v_{i}+v_{j}\right)\left(N_{i}+N_{j}\right)\right]
\end{gathered}
$$

The operator $C_{i j}$ is diagonal and the vibrational quantum numbers $v_{i}$ have been used instead of $m_{i}$. In practical calculations, it is sometime convenient to substract from $C_{i j}$ a contribution that can be absorbed in the Casimir operators of the individual modes $i$ and $j$, thus considering an operator $C_{i j}{ }^{\prime}$ whose matrix elements are

$$
\begin{aligned}
& \left\langle N_{i}, v_{i} ; N_{j}, v_{j}\left|C_{i j}{ }^{\prime}\right| N_{i}, v_{i} ; N_{j}, v_{j}\right\rangle=4\left[\left(v_{i}+v_{j}\right)^{2}\right. \\
& \left.-\left(v_{i}+v_{j}\right)\left(N_{i}+N_{j}\right)\right]+\left[\left(N_{i}+N_{j}\right) / N_{i}\right] 4\left(N_{i} v_{i}-v_{i}^{2}\right) \\
& \quad+\left[\left(N_{i}+N_{j}\right) / N_{j}\right] 4\left(N_{j} v_{j}-v_{j}^{2}\right) .
\end{aligned}
$$

The second term is the Majorana operator, $M_{i j}$. This operator has both diagonal and off-diagonal matrix elements

$$
\begin{gathered}
\left\langle N_{i}, v_{i} ; N_{j}, v_{j}\left|M_{i j}\right| N_{i}, v_{i} ; N_{j}, v_{j}\right\rangle=\left(N_{i} v_{j}+N_{j} v_{i}-2 v_{i} v_{j}\right) \\
\left\langle N_{i}, v_{i}+1 ; N_{j}, v_{j}-1\left|M_{i j}\right| N_{\mathrm{i}}, v_{i} ; N_{j}, v_{j}\right\rangle \\
=-\left[v_{j}\left(v_{i}+1\right)\left(N_{i}-v_{i}\right)\left(N_{j}-v_{j}+1\right)\right]^{1 / 2} \\
\left\langle N_{i}, v_{i}-1 ; N_{j}, v_{j}+1\left|M_{i j}\right| N_{i}, v_{i} ; N_{j}, v_{j}\right\rangle \\
=-\left[v_{i}\left(v_{j}+1\right)\left(N_{j}-v_{j}\right)\left(N_{i}-v_{i}+1\right)\right]^{1 / 2}
\end{gathered}
$$

The Majorana operators $M_{i j}$ annihilâtes one quantum of vibration in bond $\mathrm{i}$ and create one in bond $j$, or vice versa.

The total Hamiltonian for $\mathrm{n}$ stretching vibrations is

$$
H=E_{0}+\sum_{i=1}^{n} A_{i} C_{i}+\sum_{i\langle j}^{n} A_{i j} C_{i j}+\sum_{i\langle j}^{n} \lambda_{i j} M_{i j}
$$

If $\lambda_{i j}=0$ the vibrations have local behavior. As the $\lambda_{i j} \mathrm{~s}$ increase, one goes more and more into normal vibrations.

\subsection{Symmetry- Adapted Operators}

In polyatomic molecules, the geometric point group symmetry of the molecule plays an important role. States must transform according to representations of the point symmetry group. In the absence of the Majorana operators $M_{i j}$, states are degenerate. The introduction of the Majorana operators has two effects: 1) it splits the degeneracies of figure and 2) in addition it generates states with the appropriate transformation properties under the point group. In order to achieve this result the $\lambda_{i j}$ must be chosen in an appropriate way that reflects the geometric symmetry of the molecule. The total Majorana operator 


$$
S=\sum_{i<j}^{n} M_{i j}
$$

is divided into subsets reflecting the symmetry of the molecule

$$
S=S^{\prime}+S^{\prime \prime}+-\cdot--------- \text {. }
$$

The operators $S^{\prime}, S^{\prime \prime}$, ------ are the symmetry-adapted operators. The construction of the symmetry-adapted operators of any molecule become clear in the following sections where the cases of Porphyrins $\left(D_{4 h}\right)$ discussed.

\subsection{Hamiltonian for Bending Vibrations}

We emphasize once more that the quantization scheme of bending vibrations in $U(2)$ is rather different from $\mathrm{U}(4)$ and implies a complete separation between rotations and vibrations. If this separation applies, one can quantize each bending oscillator i by means of an algebra $\mathrm{U}_{\mathrm{i}}(2)$ as in Eq.2. The Poschl-Teller Hamiltonian

$$
H\left(p_{s}, s\right)=p_{s}^{2} / 2 \mu-D / \cosh ^{2}(\alpha s)
$$

Where we have absorbed the $\lambda(\lambda-1)$ part into $\mathrm{D}$, can be written, in the algebraic approach, as

$$
H_{i}=\varepsilon_{0 i}+A_{i} C_{i},
$$

This Hamiltonian is identical to that of stretching vibration (Eq.3). The only difference is that the coefficients $A_{i}$ in front of $C_{i}$ are related to the parameters of the potential, $\mathrm{D}$ and $\alpha$, in a way that is different for Morse and Poschl-Teller potentials. The energy eigenvalues of uncoupled Poschl-Teller oscillators are, however, still given by

$$
E=\sum_{i} \varepsilon_{i}=E_{0}-\sum_{i} 4 A_{i}\left(N_{i} v_{i}-v_{i}^{2}\right)
$$

One can then proceed to couple the oscillators as done previously and repeat the same treatment of Eqs.2, 3, and 4.

\subsection{The Metalloporphyrin Molecule}

The construction of the symmetry-adapted operators and of the Hamiltonian operator of polyatomic molecule illustrated using the example of Metalloporphyrin. In order to do the construction, draw a figure corresponding to the geometric structure of the molecule (Figure 1). Number of degree of freedom we wish to describe.

By inspection of the figure, one can see that two types of interactions in Metalloporphyrin:

1) First-neighbor couplings (Adjacent interactions)

2) Second-neighbor couplings (Opposite interactions)

With $D_{4 h}$ symmetry here, the operators (on the basis of the considerations mentioned above) are

$$
\begin{gathered}
S=\sum_{i<j}^{n} M_{i j}, S^{\prime}=\sum_{i<j}^{n} c_{i j}^{\prime} M_{i j}, S^{\prime \prime}=\sum_{i<j}^{n} c^{\prime \prime}{ }_{i j} M_{i j} . \\
\mathrm{c}^{\prime}{ }_{12}=\mathrm{c}^{\prime}{ }_{23}=\mathrm{c}^{\prime}{ }_{34}=\mathrm{c}^{\prime}{ }_{45}=-\cdots-=1, \mathrm{c}^{\prime}{ }_{13}=\mathrm{c}^{\prime}{ }_{24}=\mathrm{c}^{\prime}{ }_{35}=\mathrm{c}^{\prime}{ }_{46}
\end{gathered}
$$

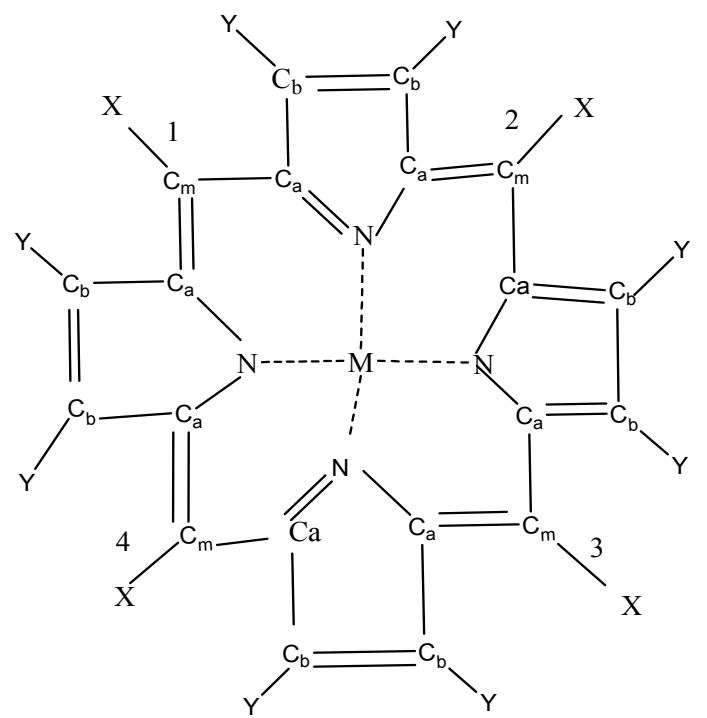

Figure 1. The structure of Metalloporphyrin.

$$
\begin{aligned}
& \mathrm{Ni}(\mathrm{OEP}) \rightarrow \mathrm{X}=\mathrm{H}, \quad \mathrm{Y}=\text { Ethyl, } \\
& \mathrm{Ni}(\mathrm{OEP})-\mathrm{d}_{4} \rightarrow \mathrm{X}=\mathrm{D}, \quad \mathrm{Y}=\text { Ethyl. } \\
& \mathrm{Ni}(\mathrm{TPP}) \rightarrow \mathrm{X}=\text { Phenyl, } \mathrm{Y}=\mathrm{H}, \\
& \mathrm{Cu}(\mathrm{TMP}) \rightarrow \mathrm{X}=\text { Mesityl, } \mathrm{Y}=\mathrm{H} \text {. } \\
& \text { Ni Por } \rightarrow \mathrm{X}=\mathrm{H}, \quad \mathrm{Y}=\mathrm{H} \text {. } \\
& \text { = - - - - - =0, } \\
& \mathrm{c}^{\prime \prime}{ }_{12}=\mathrm{c}^{\prime \prime}{ }_{23}=\mathrm{c}^{\prime \prime}{ }_{34}=\mathrm{c}^{\prime \prime}{ }_{45}=\ldots-\ldots, \mathrm{c}_{13}^{\prime \prime}=\mathrm{c}^{\prime \prime}{ }_{24}=\mathrm{c}^{\prime \prime}{ }_{35} \\
& =\mathrm{c}^{\prime \prime}{ }_{46}=-\cdots--1 \text {, }
\end{aligned}
$$

Diagonalization of $S^{\prime}$ produces states that carry representations transform according to the representations $A_{1 g}$, $B_{1 g}, A_{2 g}, B_{2 g}$, and $E_{1 u}$ of $D_{4 h}$. The $S^{\prime}$ operator is thus the "symmetry adapter" operator. This result, which, at first sight, appears to be surprising, can be easily verified by computing the characters of the representations carried by the eigenstates of $S^{\prime}$ in the usual way. Here, in this case the value of $\mathrm{n}$ is either $4(j=4, i=3)$ or $8(j=8, i=$ 7).

\section{RESULTS AND DISCUSSIONS}

We have used U (2) algebraic model to study vibrational spectra of the Porphyrin and its substituted form molecules. The fitting algebraic parameters are $A, A^{\prime}, \lambda, \lambda^{\prime}$ and $N$ (Vibron number). The values of Vibron number $(N)$ can be determined by the relation

$$
N_{i}=\frac{\omega_{e}}{\omega_{e} x_{e}}-1,(i=1,2, \ldots \ldots)
$$

where $\omega_{e}$ and $\omega_{e} x_{e}$ are the spectroscopic constants of diatomic molecules [27]. This numerical value must be seen as initial guess; depending on the specific molecular structure, one can expect changes in such an estimate, which, however, should not be larger than $\pm 20 \%$ of the original value (Eq.18). The Vibron number $N$ between 
the diatomic molecule C-C, C-H and C-D are 140, 44 and 59 respectively. From the figure 1, it is noticed that some of the bonds are equivalent. It may be noted that during the calculation of the vibrational frequencies of Porphyrins and substituted forms, the value of $\mathrm{N}$ is kept fixed and not used as free parameter.

The second step is to obtain a starting guess for the parameter $A$. As such, the expression for the singleoscillator fundamental mode as

$$
E(v=1)=-4 A(N-1) .
$$

In the present case we have three different energies, corresponding to symmetric and antisymmetric combinations of the different local modes. A possible strategy is to use the center of gravity of these modes, so the guess for

$$
\bar{A}=\frac{\bar{E}}{4(1-N)}
$$

The third step is to obtain an initial guess for $\lambda$. Its role is to split the initially degenerate local modes, placed here at the common value $E$ used in Eq.19. Such an estimate is obtained by considering the simple matrix structure, we can find

$$
\begin{gathered}
\lambda=\frac{\left|E_{E u}-E_{A 1 g}\right|}{2 N} \\
\& \quad \lambda^{!}=\frac{\left|E_{B 2 g}-E_{A 1 g}\right|}{4 N}
\end{gathered}
$$

Finally a numerical fitting procedure is to be carried to adjust (in a least- square sense, for example) the parameters $A$ and $\lambda$ starting from values Eq.20 and Eq.21, and $A^{\prime}$ (whose initial guess can be zero).

Using the Eqs.20, 21 and 22, $A, \lambda$ and $\lambda^{\prime}$ are calculated $[4,5-7,27]$ using the available data points. We have taken $\lambda^{\prime \prime}=0$ (In this case, the next nearest neighbor couplings are omitted). As one can see from Table $1 \&$ Table 2, the agreement with experiment is good and thus we think that the parameter set of Table $4 \&$ Table 5 can be used reliably to compute energies of highly excited overtones. We note that in Table 2 \& Table 3, there are many predicted overtones that have not been studied experimentally. We have explicit calculations up to the second overtone (energy up to $\approx 10000 \mathrm{~cm}^{-1}$ ).

We have used the algebraic Hamiltonian to study the highly excited vibrational levels of the molecule $\mathrm{Ni}$ (TPP), $\mathrm{Cu}$ (OEP), Mg (OEP), Cu (TPP), Cu (TMP), Ni Porphyrin, $\mathrm{Ni}$ (OEP) and its substitution form $\mathrm{Ni}$ (OEP) $-\mathrm{d}_{4}$. Eight bands are studied, which can be labeled the $\mathrm{C}_{\mathrm{m}}-\mathrm{H}, \mathrm{C}_{\mathrm{b}}-\mathrm{C}_{\mathrm{b}}$ and only for $\mathrm{Ni}(\mathrm{OEP})-\mathrm{d}_{4}$ the bands labeled are $C_{m}-D, C_{b}-C_{b}$ respectively. The highly excited vibrational levels, calculated by using the algebraic Hamiltonian Eq.11, are shown in Figures 2, 3, 4, and 5 (The detail calculated vibrational energy levels are listed in Tables 3). Figures 2 and $\mathbf{3}$ gives the levels corresponding to the $\mathrm{C}_{\mathrm{m}}-\mathrm{H}, \mathrm{C}_{\mathrm{b}}-\mathrm{C}_{\mathrm{b}}$ of $\mathrm{Ni}$ (TPP). Figures 4 and 5 gives the levels corresponding to the $\mathrm{C}_{\mathrm{m}}-\mathrm{H}, \mathrm{C}_{\mathrm{b}}-\mathrm{C}_{\mathrm{b}}$ of $\mathrm{Cu}$ (TPP). Figures 6 and 7 gives the levels corresponding to the $\mathrm{C}_{\mathrm{m}}-\mathrm{H}, \mathrm{C}_{\mathrm{b}}-\mathrm{C}_{\mathrm{b}}$ of $\mathrm{Cu}$ (TMP). Figures 8 and 9 gives the levels corresponding to the $\mathrm{C}_{\mathrm{m}}-\mathrm{D}, \mathrm{C}_{\mathrm{b}}-\mathrm{C}_{\mathrm{b}}$ of $\mathrm{Ni}$ (OEP) $-\mathrm{d}_{4}$. When the quantum number $v$ increases in a fixed band, the numbers of energy levels increase rapidly. Usually, the degeneracy or quanti-degeneracy of energy levels is called clustering. It may be seen from Figures 2, 3, 4, 5, 6, 7, 8 and 9 that the vibrational energy levels of Porphyrin and its substituted form make up clusters.

\section{CONCLUSIONS}

In this paper, we have presented a systematic analysis of vibrational spectra of Porphyrin and its substituted forms in the algebraic framework making use of the one-dimensional Vibron model i.e. U (2) Vibron model.

Using the $U$ (2) algebraic model Hamiltonian, the stretching frequencies of $\mathrm{C}_{\mathrm{b}}-\mathrm{C}$ and Pyrrol breathing up to Second overtone $(v=2)$, the combinational bands of Nickel Octaethyl Porphyrin [Ni(OEP)] and its substituted form Ni(OEP)- $\mathrm{d}_{4}$ molecules are given in Table 2 . However, due to lack of sufficient data base, we could not compare the calculated vibrational frequencies with that of observed data of Nickel Metalloporphyrin and its substituted forms at higher overtones. This study is useful to the experimentalist to analyze the predicted vibrational frequencies with the observed data. The model pre sented here describes the splitting of local stretching/bending modes due to residual interbond interactions. The splitting pattern determines the nature of interaction (Parameter $\lambda \lambda^{\prime}$ ). Once we get the parameter, we predict the splitting pattern of overtones. It is worth to point out that most applications of previous algebraic models available in literature [28-33] are restricted to vibrations of Bio-molecules.

The importance of the method is that it allows one to do a global analysis of all molecular species in terms of few algebraic parameters. In turn provides a way to make assignments of unknown levels or to check assignments of known levels. The study of vibrational excitations of these bio-molecules (proteins) has numerous importance not only in human life but also in scientific research.

\section{ACKNOWKEDGEMENTS}

The author Dr. Srinivasa Rao Karumuri would like to thank Prof. Thomson G Spiro for providing the necessary literature for this study. The authors Dr.Srinivasa Rao Karumuri and Prof. Ramendu Bhattacharjee are grateful to the DST, New Delhi for supporting this work. The author is very much grateful to the anonymous referee of this paper for his valuable suggestions and comments, which greatly helped to improve the quality of the paper. 
Table 1. Comparison between the Observed and Calculated frequencies of the fundamental vibrations of Porphyrin and its substitution forms.

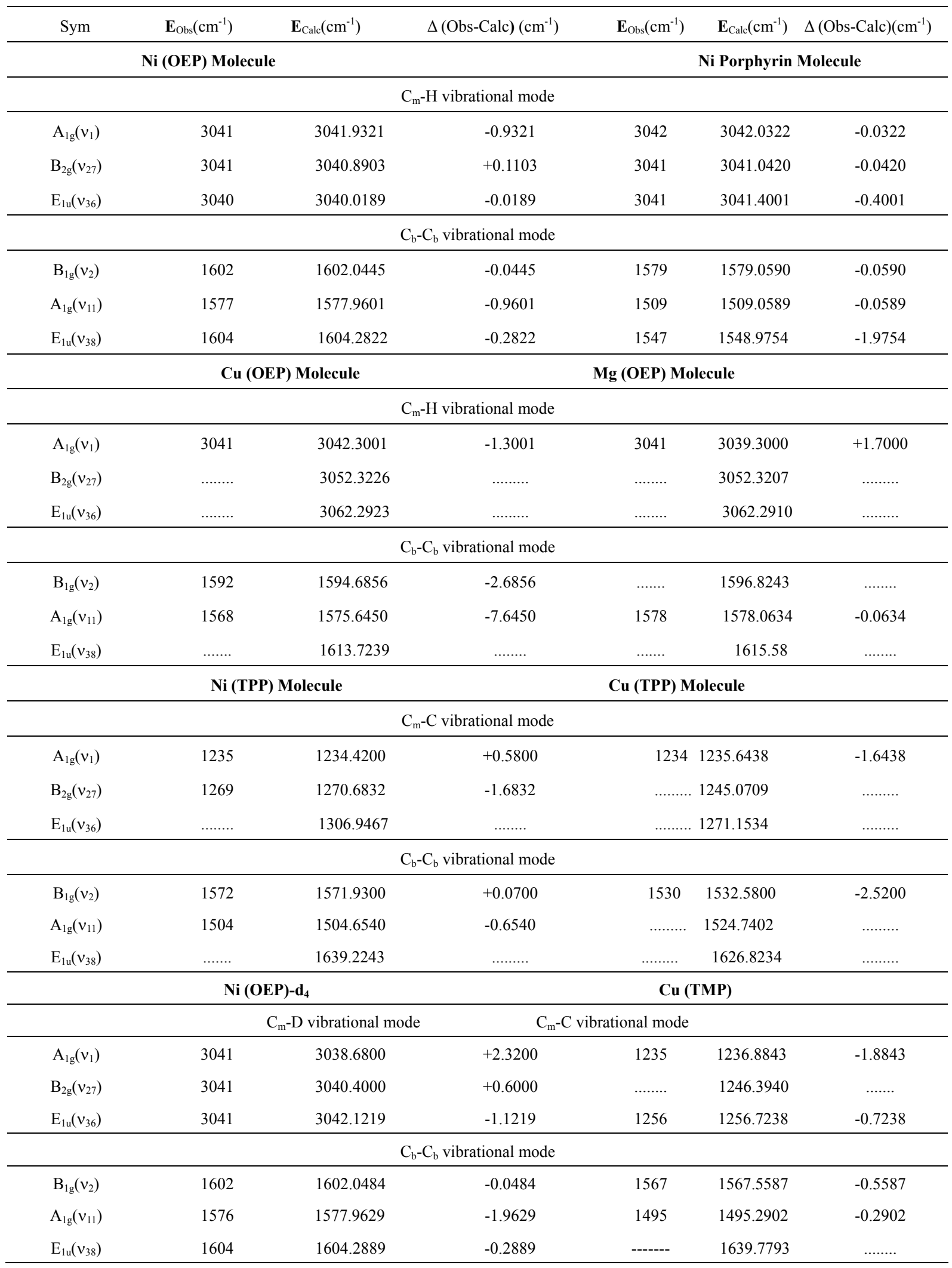


Table 2. Comparison between the Observed and Calculated frequencies of $\mathrm{C}_{\mathrm{b}}-\mathrm{C}$ stretching vibrations of Nickel Octaethyl Porphyrin $[\mathrm{Ni}(\mathrm{OEP})]$ and its substituted form i.e $\mathrm{Ni}(\mathrm{OEP})-\mathrm{d}_{4}$.

\begin{tabular}{|c|c|c|c|c|c|c|}
\hline$n$ species & $\mathbf{E}_{\mathrm{Obs}}\left(\mathrm{cm}^{-1}\right)$ & $\mathbf{E}_{\text {Calc }}\left(\mathrm{cm}^{-1}\right)$ & $\left(\right.$ Obs-Calc) $\left(\mathrm{cm}^{-1}\right)$ & $\mathbf{E}_{\mathrm{Obs}}\left(\mathrm{cm}^{-1}\right)$ & $\mathbf{E}_{\text {Calc }}\left(\mathrm{cm}^{-1}\right)$ & $\Delta(\mathrm{Obs}-\mathrm{Calc})\left(\mathrm{cm}^{-1}\right)$ \\
\hline & & \multicolumn{2}{|l|}{ Ni(OEP) Molecule } & \multicolumn{2}{|c|}{ Ni(OEP)-d4 Molecule } & \\
\hline \multicolumn{7}{|c|}{$\mathrm{C}_{\mathrm{b}}-\mathrm{C}$ vibrational mode } \\
\hline $\mathrm{A}_{1 \mathrm{~g}}\left(v_{5}\right)$ & 1025 & 1043.3471 & -18.3471 & 1026 & 1024.1729 & 1.8271 \\
\hline $\mathrm{B}_{1 \mathrm{~g}}\left(v_{14}\right)$ & 1151 & 1134.4480 & 16.5520 & 1187 & 1168.2545 & 18.7455 \\
\hline $\mathrm{A}_{2 \mathrm{~g}}\left(\mathrm{v}_{23}\right)$ & 1022 & 1045.5548 & -23.5548 & 1029 & 1026.7901 & 2.2099 \\
\hline $\mathrm{B}_{2 \mathrm{~g}}\left(v_{31}\right)$ & 1019 & 1010.5280 & 8.4720 & 999 & 1006.2923 & -7.2923 \\
\hline $\mathrm{E}_{\mathrm{u}}\left(\mathrm{v}_{43}\right)$ & $\ldots \ldots$ & 1159.4680 & $\ldots \ldots \ldots$ & & 1165.7804 & \\
\hline $\mathrm{E}_{\mathrm{u}}\left(\mathrm{v}_{45}\right)$ & $\ldots \ldots$ & 994.4080 & $\ldots \ldots \ldots$ & & 978.6798 & \\
\hline \multicolumn{7}{|c|}{ First Overtone } \\
\hline$A_{1 g}\left(v_{5}+v_{6}\right)$ & 1831 & 1837.3438 & -6.3438 & 1828 & 1823.6649 & 4.3351 \\
\hline $\mathrm{E}_{\mathrm{u}}$ & & 1981.8380 & & & 1924.4935 & \\
\hline $\mathrm{B}_{1 \mathrm{~g}}$ & & 2039.4881 & & & 1948.6704 & \\
\hline $\mathrm{A}_{2 \mathrm{~g}}$ & & 2040.7594 & & & 2019.2772 & \\
\hline $\mathrm{E}_{\mathrm{u}}$ & & 2089.0281 & & & 2088.5504 & \\
\hline $\mathrm{E}_{\mathrm{u}}$ & & 2126.0643 & & & 2189.3792 & \\
\hline$A_{1 g}\left(v_{22}+v_{23}\right)$ & 2135 & 2145.5906 & -10.5906 & 2216 & 2246.3847 & -30.3847 \\
\hline $\mathrm{E}_{\mathrm{u}}$ & & 2190.3683 & & & 2289.3098 & \\
\hline $\mathrm{E}_{\mathrm{u}}$ & & 2261.3456 & & & 2293.3070 & \\
\hline $\mathrm{B}_{1 \mathrm{~g}}$ & & 2289.6720 & & & 2309.3572 & \\
\hline $\mathrm{E}_{\mathrm{u}}$ & & 2324.6758 & & & 2365.8686 & \\
\hline $\mathrm{E}_{\mathrm{u}}$ & & 2356.7683 & & & 2371.8268 & \\
\hline $\mathrm{E}_{\mathrm{u}}$ & & 2454.6856 & & & 2398.7437 & \\
\hline $\mathrm{E}_{\mathrm{u}}$ & & 2488.9103 & & & 2404.7578 & \\
\hline$A_{1 g}\left(v_{28}+v_{31}\right)$ & 2494 & 2490.1380 & 3.8610 & 2460 & 2452.6969 & 7.3031 \\
\hline $\mathrm{B}_{1 \mathrm{~g}}$ & & 2497.4836 & & & 2479.8699 & \\
\hline \multicolumn{7}{|c|}{ Second Overtone } \\
\hline $\mathrm{A}_{1 \mathrm{~g}}$ & & 2502.3920 & & & 2529.2334 & \\
\hline $\mathrm{E}_{\mathrm{u}}$ & & 2519.2033 & & & 2530.8538 & \\
\hline $\mathrm{A}_{2 \mathrm{~g}}\left(\mathrm{v}_{3}+\mathrm{v}_{23}\right)$ & 2541 & 2537.2890 & 3.7110 & 2539 & 2541.9693 & -2.9693 \\
\hline $\mathrm{A}_{2 \mathrm{~g}}\left(\mathrm{v}_{14}+\mathrm{v}_{29}\right)$ & 2568 & 2569.3040 & -1.3040 & 2607 & 2609.5773 & -2.5773 \\
\hline $\mathrm{E}_{\mathrm{u}}$ & & 2582.2093 & & & 2601.3572 & \\
\hline$A_{1 g}\left(v_{19}+v_{23}\right)$ & 2614 & 2606.4803 & 7.5197 & 2604 & 2599.9575 & 4.0425 \\
\hline $\mathrm{B}_{1 \mathrm{~g}}\left(v_{3}+v_{14}\right)$ & 2670 & 2689.3094 & -19.3094 & 2710 & 2703.3547 & 6.6453 \\
\hline $\mathrm{E}_{\mathrm{u}}$ & & 2730.3802 & & & 2734.8643 & \\
\hline $\mathrm{A}_{1 \mathrm{~g}}$ & & 2772.9689 & & & 2767.8346 & \\
\hline $\mathrm{E}_{\mathrm{u}}$ & & 2826.3283 & & & 2798.3468 & \\
\hline \multicolumn{7}{|c|}{ Pyr breathing vibrational mode } \\
\hline$A_{1 g}\left(v_{6}\right)$ & 806 & 804.1759 & 1.8241 & 802 & 801.6378 & 0.3622 \\
\hline $\mathrm{B}_{1 \mathrm{~g}}\left(v_{15}\right)$ & 761 & 751.2534 & 9.7466 & 758 & 759.7356 & -1.7356 \\
\hline $\mathrm{E}_{\mathrm{u}}\left(v_{47}\right)$ & $\ldots \ldots$ & 765.7932 & & & 783.3495 & \\
\hline \multicolumn{7}{|c|}{ First Overtone } \\
\hline $\mathrm{A}_{1 \mathrm{~g}}$ & & 1496.0304 & & & 1398.7654 & \\
\hline $\mathrm{E}_{\mathrm{u}}$ & & 1524.7395 & & & 1404.8475 & \\
\hline $\mathrm{E}_{\mathrm{u}}$ & & 1548.6704 & & & 1439.8364 & \\
\hline $\mathrm{B}_{1 \mathrm{~g}}\left(v_{6}+v_{16}\right)$ & 1557 & 1559.2772 & -2.2772 & 1481 & 1476.8364 & 4.1636 \\
\hline $\mathrm{E}_{\mathrm{u}}$ & & 1668.5904 & & & 1558.8239 & \\
\hline
\end{tabular}




\begin{tabular}{|c|c|c|c|c|c|c|}
\hline $\mathrm{E}_{\mathrm{u}}$ & & 1782.3804 & & & 1702.7529 & \\
\hline $\mathrm{A}_{1 \mathrm{~g}}\left(v_{5}+v_{6}\right)$ & 1831 & 1864.0326 & -33.0326 & 1828 & 1825.4704 & 2.5296 \\
\hline $\mathrm{E}_{\mathrm{u}}$ & & 1893.4056 & & & 1870.7354 & \\
\hline $\mathrm{E}_{\mathrm{u}}$ & & 1899.0328 & & & 1892.7253 & \\
\hline \multicolumn{7}{|c|}{ Second Overtone } \\
\hline$A_{2 g}\left(v_{6}+v_{21}\right)$ & 2109 & 2131.9844 & -22.9844 & 2114 & 2103.7364 & 10.2636 \\
\hline$B_{1 g}\left(v_{6}+v_{20}\right)$ & 2144 & 2148.4379 & -4.4379 & 2148 & 2152.7856 & -4.7856 \\
\hline $\mathrm{A}_{1 \mathrm{~g}}\left(v_{4}+v_{6}\right)$ & 2184 & 2231.9844 & -47.9844 & 2189 & 2190.4356 & -1.4356 \\
\hline $\mathrm{E}_{\mathrm{u}}$ & & 2260.5412 & & & 2237.2455 & \\
\hline $\mathrm{E}_{\mathrm{u}}$ & & 2339.6766 & & & 2290.5472 & \\
\hline $\mathrm{A}_{1 \mathrm{~g}}$ & & 2310.9441 & & & 2367.3864 & \\
\hline $\mathrm{E}_{\mathrm{u}}$ & & 2363.5840 & & & 2443.9763 & \\
\hline $\mathrm{E}_{\mathrm{u}}$ & & 2417.2044 & & & 2489.8322 & \\
\hline $\mathrm{E}_{\mathrm{u}}$ & & 2481.1734 & & & 2547.3453 & \\
\hline $\mathrm{B}_{1 \mathrm{~g}}$ & & 2542.5424 & & & 2601.3643 & \\
\hline $\mathrm{A}_{2 \mathrm{~g}}\left(v_{5}+v_{19}\right)$ & 2626 & 2616.8038 & 9.1962 & 2628 & 2629.7439 & -1.7439 \\
\hline $\mathrm{E}_{\mathrm{u}}$ & & 2683.3023 & & & 2668.5233 & \\
\hline
\end{tabular}

Observed values taken from the reference [34-36]

Table 3. Calculated excited vibrational frequencies of $\mathrm{C}_{\mathrm{m}}-\mathrm{H}$ stretching vibrations of Porphyrins \& its substituted forms $\left(\mathrm{Cm}^{-1}\right)$.

\begin{tabular}{|c|c|c|c|c|c|c|c|c|c|}
\hline & Sym & $\mathrm{E}_{\text {Calc }}$ & $E_{\text {Obs }}$ & $\mathrm{E}_{\text {Calc }}$ & & $\mathrm{E}_{\mathrm{Obs}}$ & $\mathrm{E}_{\mathrm{CalC}}$ & $\mathrm{E}_{\text {Obs }}$ & $\mathrm{E}_{\text {Calc }}$ \\
\hline & \multicolumn{2}{|c|}{ Ni (OEP) } & \multicolumn{2}{|c|}{ Ni Porphyrin } & \multicolumn{2}{|c|}{$\mathrm{Cu}$ (OEP) } & \multicolumn{3}{|c|}{ Mg (OEP) } \\
\hline \multirow{3}{*}{$\mathrm{n}=1$} & $\mathrm{~A}_{1 \mathrm{~g}}\left(v_{1}\right)$ & 3041 & 3041.93 & 3042 & 3042.03 & 3041 & 3042.30 & 3041 & 3042.30 \\
\hline & $\mathrm{B}_{2 \mathrm{~g}}\left(v_{27}\right)$ & 3041 & 3040.89 & 3041 & 3041.04 & $\ldots \ldots . .$. & 3052.32 & $\ldots \ldots .$. & 3052.32 \\
\hline & $\mathrm{E}_{1 \mathrm{u}}\left(v_{36}\right)$ & 3040 & 3040.01 & 3041 & 3041.40 & ......... & 3062.29 & $\ldots \ldots . .$. & 3062.29 \\
\hline \multirow{7}{*}{$\mathrm{n}=2$} & $\mathrm{E}_{1 \mathrm{u}}$ & & 5941.47 & & 5951.92 & & 5945.15 & & 5922.78 \\
\hline & $\mathrm{B}_{1 \mathrm{~g}}$ & & 5942.44 & & 5951.37 & & 5946.23 & & 5923.63 \\
\hline & $\mathrm{A}_{2 \mathrm{~g}}$ & & 5944.38 & & 5951.73 & & 5947.14 & & 5924.36 \\
\hline & $\mathrm{E}_{1 \mathrm{u}}$ & & 5945.16 & & 5952.00 & & 5948.14 & & 5924.89 \\
\hline & $\mathrm{E}_{1 \mathrm{u}}$ & & 5946.84 & & 5953.35 & & 5986.70 & & 5924.65 \\
\hline & $\mathrm{E}_{1 \mathrm{u}}$ & & 5947.29 & & 5953.72 & & 5994.28 & & 5925.15 \\
\hline & $\mathrm{E}_{1 \mathrm{u}}$ & & 5948.07 & & 5954.35 & & 6007.48 & & 5925.94 \\
\hline \multirow{12}{*}{$\mathrm{n}=3$} & $\mathrm{~A}_{1 \mathrm{~g}}$ & & 8707.29 & & 8730.98 & & 8708.54 & & 8676.16 \\
\hline & $\mathrm{E}_{1 \mathrm{u}}$ & & 8708.52 & & 8731.73 & & 8709.53 & & 8676.95 \\
\hline & $\mathrm{E}_{\mathrm{lu}}$ & & 8708.97 & & 8731.97 & & 8709.90 & & 8677.24 \\
\hline & $\mathrm{E}_{1 \mathrm{u}}$ & & 8709.75 & & 8732.33 & & 8712.60 & & 8679.38 \\
\hline & $\mathrm{B}_{1 \mathrm{~g}}$ & & 8712.30 & & 8731.90 & & 8713.53 & & 8680.12 \\
\hline & $\mathrm{E}_{1 \mathrm{u}}$ & & 8713.45 & & 8732.96 & & 8812.42 & & 8681.44 \\
\hline & $\mathrm{E}_{1 \mathrm{u}}$ & & 8715.91 & & 8735.95 & & 8853.97 & & 8683.71 \\
\hline & $A_{1 g}$ & & 8716.09 & & 8735.02 & & 8858.35 & & 8683.79 \\
\hline & $\mathrm{E}_{1 \mathrm{u}}$ & & 8703.35 & & 8737.94 & & 8874.75 & & 8684.60 \\
\hline & $\mathrm{E}_{1 \mathrm{u}}$ & & 8717.14 & & 8737.94 & & 8899.68 & & 8685.87 \\
\hline & $\mathrm{B}_{1 \mathrm{~g}}$ & & 8712.13 & & 8738.08 & & 8904.67 & & 8691.29 \\
\hline & $\mathrm{E}_{1 \mathrm{u}}$ & & 8719.56 & & 8738.93 & & 8921.42 & & 8695.86 \\
\hline
\end{tabular}

Calculated excited vibrational frequencies of $\mathrm{C}_{b^{-}} \mathrm{C}_{\mathrm{b}}$ stretching vibrations of Porphyrins \& its substituted forms Sym $\begin{array}{llll}\mathrm{E}_{\text {Obs }} & \mathrm{E}_{\text {Calc }} & \mathrm{E}_{\text {Obs }} & \mathrm{E}_{\text {Calc }}\end{array}$ $\mathrm{E}_{\text {Obs }} \quad \mathrm{E}_{\mathrm{CalC}}$ $\mathrm{E}_{\mathrm{Obs}} \mathrm{E}_{\mathrm{Calc}}$ 


\begin{tabular}{|c|c|c|c|c|c|c|c|c|c|}
\hline & \multicolumn{2}{|c|}{ Ni (OEP) } & \multicolumn{2}{|c|}{ Ni Por } & \multicolumn{2}{|c|}{$\mathrm{Cu}(\mathrm{OEP})$} & \multicolumn{3}{|c|}{ Mg (OEP) } \\
\hline & $\mathrm{B}_{\mathrm{lg}}\left(v_{2}\right)$ & 1602 & 1602.04 & 1579 & 1579.05 & 1592 & 1594.68 & & 1596.82 \\
\hline \multirow[t]{5}{*}{$\mathrm{n}=1$} & $\mathrm{~A}_{1 \mathrm{~g}}\left(v_{11}\right)$ & 1577 & 1577.96 & 1509 & 1509.05 & 1568 & 1575.64 & 1578 & 1578.06 \\
\hline & $\mathrm{E}_{1 \mathrm{u}}\left(\mathrm{v}_{38}\right)$ & 1604 & 1604.28 & 1547 & 1548.97 & & 1613.72 & & 1615.58 \\
\hline & $\mathrm{A}_{2 \mathrm{~g}}$ & & 3143.88 & & 3021.25 & & 3138.57 & & 3137.07 \\
\hline & $\mathrm{E}_{1 \mathrm{u}}$ & & 3159.17 & & 3033.88 & & 3157.61 & & 3142.67 \\
\hline & $\mathrm{B}_{2 \mathrm{~g}}$ & & 3170.90 & & 3061.13 & & 3164.55 & & 3144.71 \\
\hline \multirow[t]{9}{*}{$\mathrm{n}=2$} & $\mathrm{E}_{1 \mathrm{u}}$ & & 3183.36 & & 3161.24 & & 3176.65 & & 3148.27 \\
\hline & $\mathrm{E}_{1 \mathrm{u}}$ & & 3192.04 & & 3081.13 & & 3190.09 & & 3174.59 \\
\hline & $\mathrm{E}_{1 \mathrm{u}}$ & & 3200.82 & & 3231.24 & & 3195.69 & & 3181.43 \\
\hline & $\mathrm{E}_{1 \mathrm{u}}$ & & 3216.12 & & 3068.45 & & 3215.85 & & 3193.35 \\
\hline & $A_{1 g}$ & & 4696.54 & & 4539.77 & & 4688.79 & & 4689.66 \\
\hline & $\mathrm{E}_{1 \mathrm{u}}$ & & 4720.62 & & 4559.73 & & 4707.83 & & 4695.26 \\
\hline & $\mathrm{E}_{1 \mathrm{u}}$ & & 4729.40 & & 4567.02 & & 4714.77 & & 4697.30 \\
\hline & $\mathrm{E}_{1 \mathrm{u}}$ & & 4744.70 & & 4579.69 & & 4766.28 & & 4712.45 \\
\hline & $\mathrm{B}_{1 \mathrm{~g}}$ & & 4794.54 & & 4621.02 & & 4783.99 & & 4717.66 \\
\hline \multirow[t]{7}{*}{$\mathrm{n}=3$} & $\mathrm{E}_{\text {lu }}$ & & 4816.94 & & 4639.59 & & 4869.11 & & 4820.98 \\
\hline & $\mathrm{E}_{1 \mathrm{u}}$ & & 4865.10 & & 4679.51 & & 4878.12 & & 4827.54 \\
\hline & $\mathrm{A}_{1 \mathrm{~g}}$ & & 4868.71 & & 4682.52 & & 4894.87 & & 4839.74 \\
\hline & $\mathrm{E}_{1 \mathrm{u}}$ & & 4817.61 & & 5183.77 & & 4925.89 & & 4862.25 \\
\hline & $\mathrm{E}_{1 \mathrm{u}}$ & & 4889.18 & & 4699.48 & & 4927.63 & & 4867.88 \\
\hline & $\mathrm{B}_{1 \mathrm{~g}}$ & & 4762.34 & & 4889.77 & & 4933.51 & & 4872.57 \\
\hline & $\mathrm{E}_{\text {lu }}$ & & 4895.60 & & & & 4939.95 & & 4874.32 \\
\hline
\end{tabular}

Calculated excited vibrational frequencies of $\mathrm{C}_{\mathrm{m}}-\mathrm{C} \& \mathrm{C}_{\mathrm{m}}$-D stretching vibrations of Porphyrins \& its substituted forms

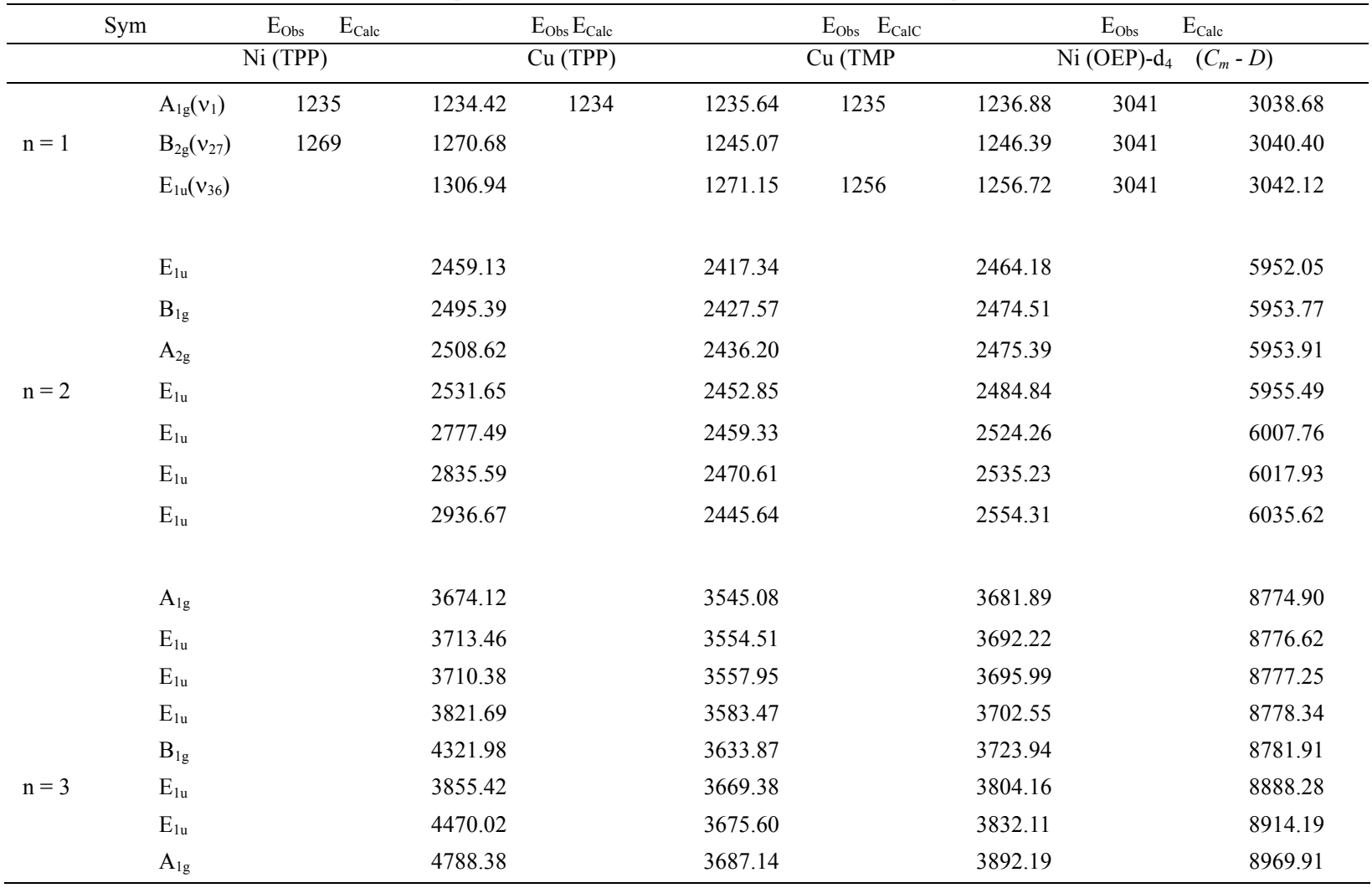




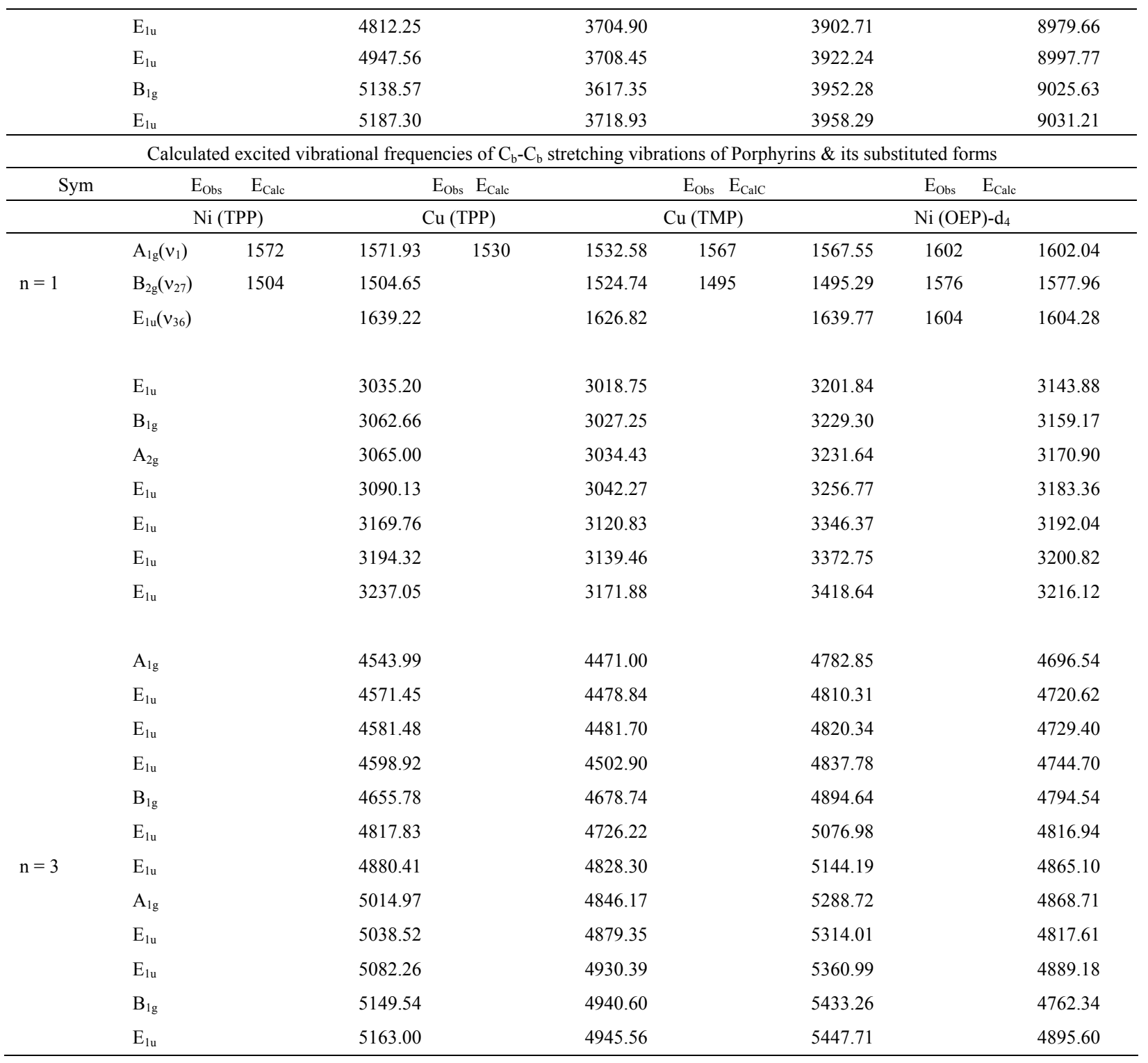

Table 4. Values ${ }^{\text {(a) }}$ of Algebraic Parameters Used in the calculation of $\mathrm{C}_{\mathrm{m}}-\mathrm{H}, \mathrm{C}_{\mathrm{m}}-\mathrm{D}$ Stretching Modes of Porphyrins and its substituted forms.

\begin{tabular}{|c|c|c|c|c|c|c|c|c|}
\hline & $\mathrm{Ni}(\mathrm{OEP})$ & $\mathrm{Cu}(\mathrm{OEP})$ & $\mathrm{Mg}(\mathrm{OEP})$ & Ni(TPP) & $\mathrm{Cu}(\mathrm{TPP})$ & $\mathrm{Cu}(\mathrm{TMP})$ & Ni Por & $\begin{array}{c}\mathrm{Ni}(\mathrm{OEP})-\mathrm{d}_{4} \\
\left(\mathrm{C}_{\mathrm{m}}-\mathrm{D}\right)\end{array}$ \\
\hline$N$ & 44 & 44 & 44 & 44 & 44 & 44 & 44 & 59 \\
\hline$A$ & -17.6802 & -17.6820 & -17.614 & -2.213 & -7.1740 & -2.2173 & -17.65 & -13.043 \\
\hline$A^{\prime}$ & -0.24 & -0.25 & -0.28 & -0.9985 & -0.4302 & -1.0182 & -1.3108 & -0.2782 \\
\hline$\lambda$ & 0.014 & 0.01136 & 0.009 & 0.1295 & 0.1072 & 0.0369 & 0.0113 & 0.0146 \\
\hline$\lambda^{\prime}$ & 0.011 & 0.012 & 0.012 & 0.5685 & 0.2018 & 0.1073 & 0.0021 & 0.2361 \\
\hline
\end{tabular}

(a) All values in $\mathrm{cm}^{-1}$ except $\mathrm{N}$, which is dimensionless. 
Table 5. Values ${ }^{(a)}$ of Algebraic Parameters Used in the calculation of $\mathrm{C}_{\mathrm{b}}-\mathrm{C}_{\mathrm{b}}$ Stretching Modes of Porphyrins and its substituted forms.

\begin{tabular}{|c|c|c|c|c|c|c|c|c|}
\hline $\mathrm{Ni}(\mathrm{OEP})$ & $\mathrm{Cu}(\mathrm{OEP})$ & $\mathrm{Mg}(\mathrm{OEP})$ & \multicolumn{2}{|c|}{ Ni(TPP) } & $\mathrm{Cu}(\mathrm{TPP})$ & $\mathrm{Cu}(\mathrm{TMP})$ & Ni Por & $\mathrm{Ni}(\mathrm{OEP})-\mathrm{d}_{4}$ \\
\hline$N$ & 140 & 140 & 140 & 140 & 140 & 140 & 140 & 140 \\
\hline$A$ & -2.83 & -2.825 & -2.835 & -2.7205 & -2.7502 & -2.8825 & -2.691 & -2.83 \\
\hline$A^{\prime}$ & -1.223 & -1.286 & -0.452 & -1.986 & 1.0921 & -1.223 & -3.216 & -1.223 \\
\hline$\lambda$ & 0.086 & 0.068 & 0.067 & 0.2403 & 0.028 & 0.2581 & 0.0713 & 0.086 \\
\hline$\lambda^{\prime}$ & 0.047 & 0.092 & 0.020 & 0.0981 & 0.1823 & 0.0981 & 0.25 & 0.047 \\
\hline
\end{tabular}

(a) All values in $\mathrm{cm}^{-1}$ except $\mathrm{N}$, which is dimensionless.

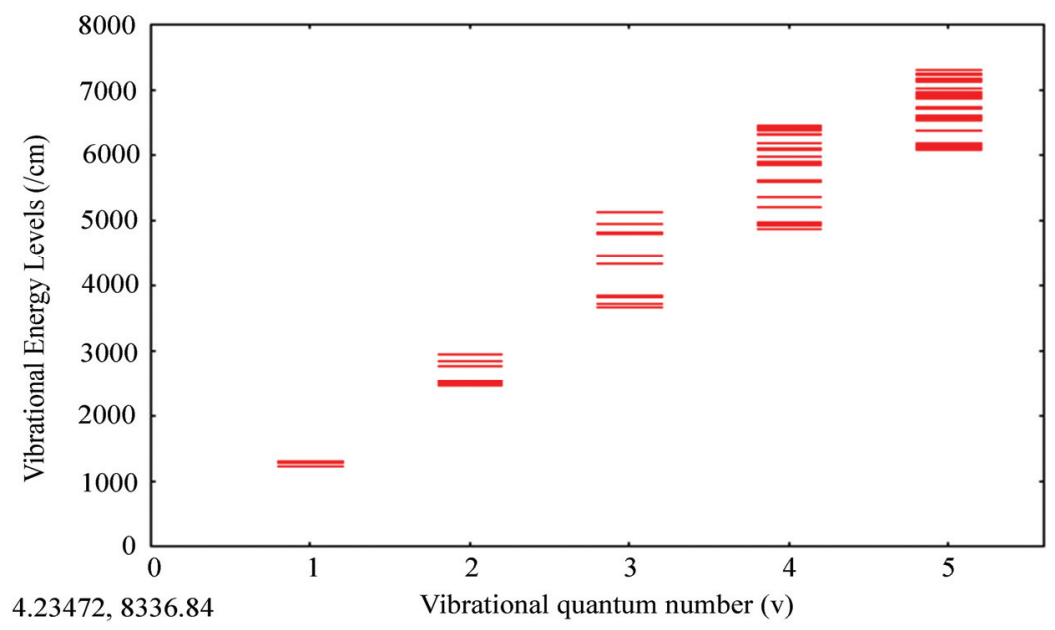

Figure 2. $\mathrm{C}_{\mathrm{m}}-\mathrm{H}$ band vibrational energy level of $\mathrm{Ni}(\mathrm{TPP})$.

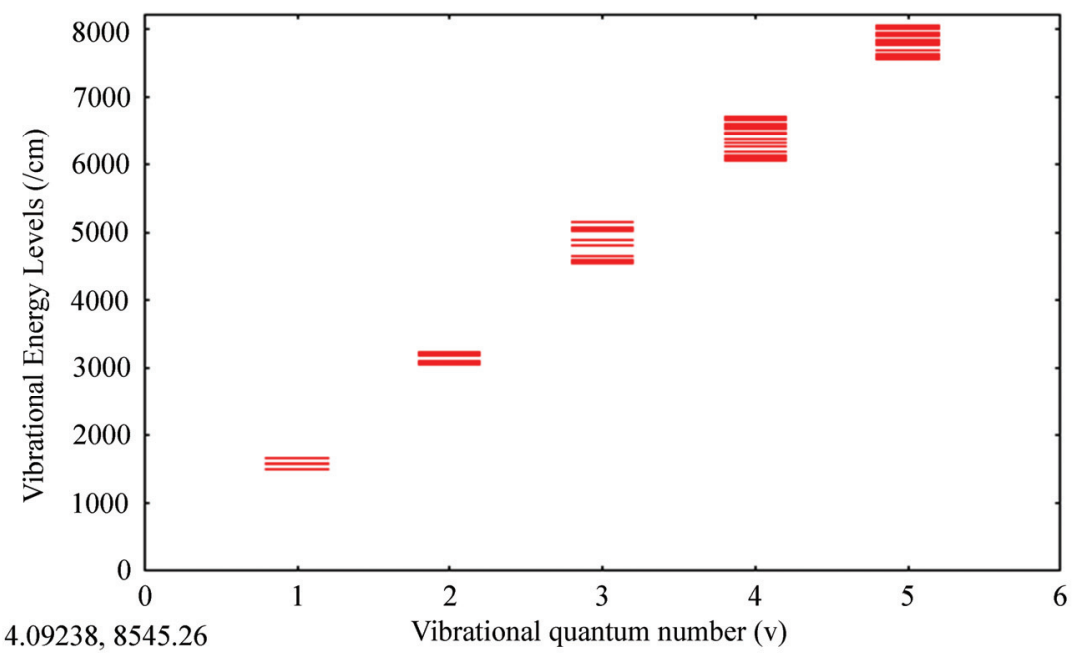

Figure 3. $\mathrm{C}_{\mathrm{b}}-\mathrm{C}_{\mathrm{b}}$ band vibrational energy level of Ni(TPP). 


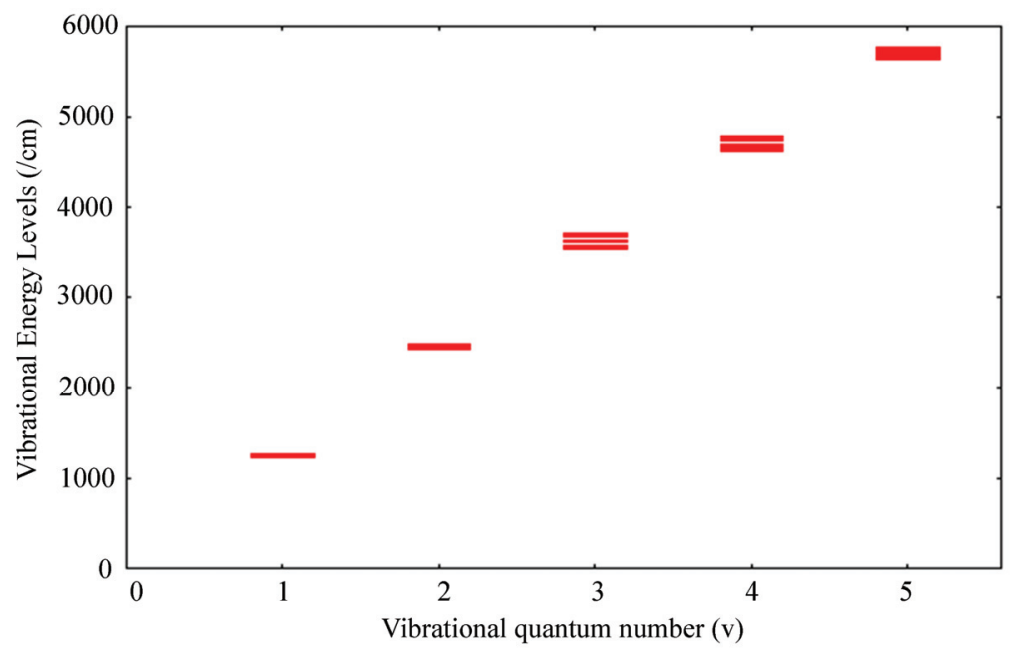

Figure 4. $\mathrm{C}_{\mathrm{m}}-\mathrm{H}$ band vibrational energy level of $\mathrm{Cu}(\mathrm{TPP})$.

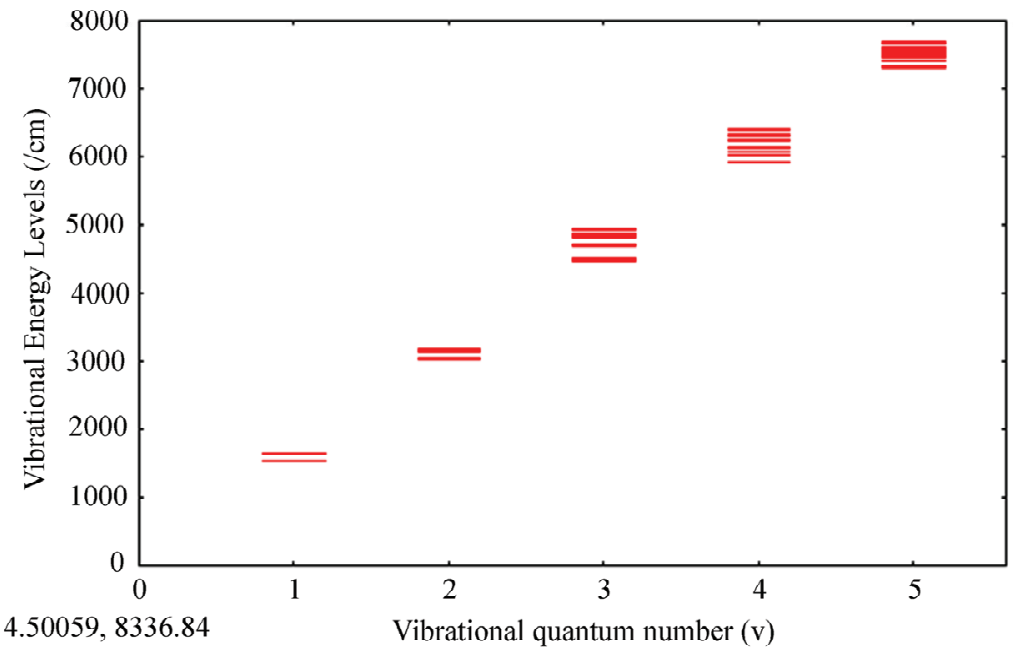

Figure 5. $\mathrm{C}_{\mathrm{b}}-\mathrm{C}_{\mathrm{b}}$ band vibrational energy level of $\mathrm{Cu}(\mathrm{TPP})$.

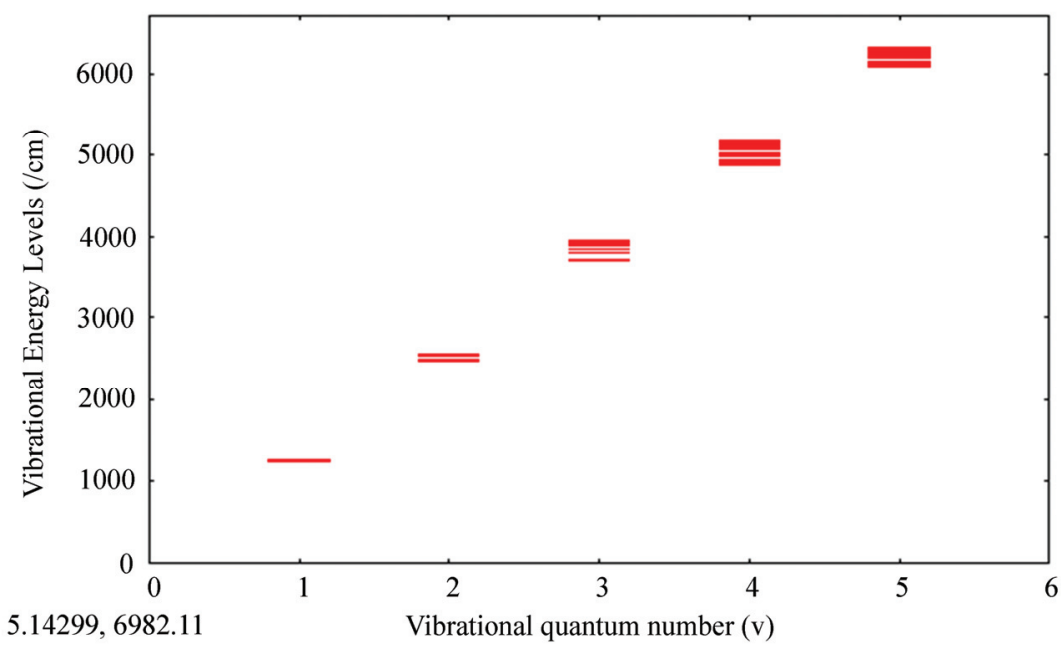

Figure 6. $\mathrm{C}_{\mathrm{m}}-\mathrm{H}$ band vibrational energy level of $\mathrm{Cu}(\mathrm{TMP})$. 


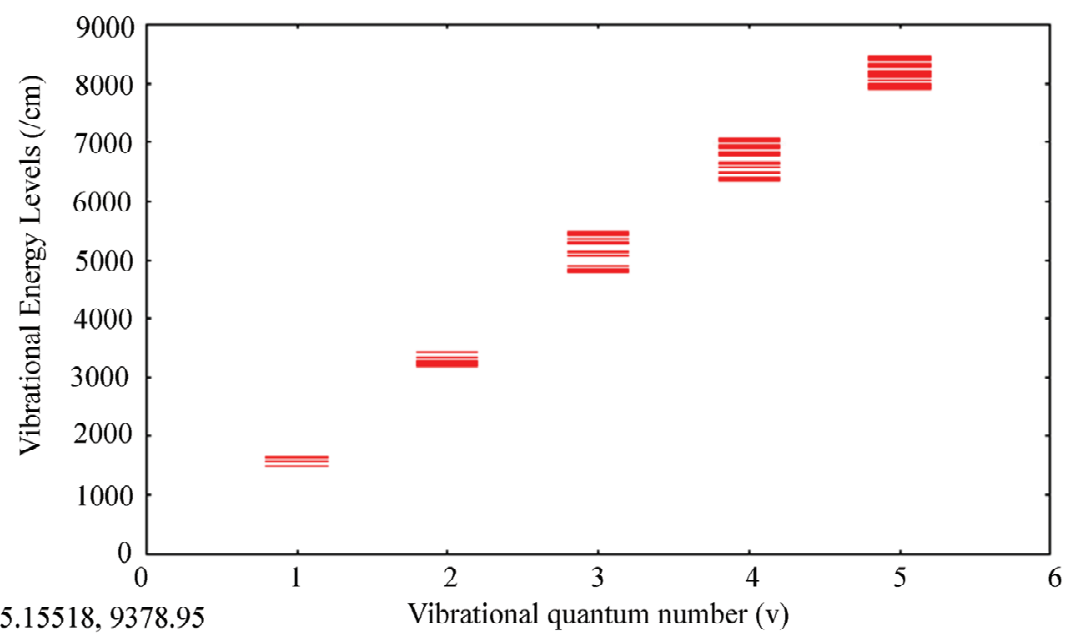

Figure 7. $\mathrm{C}_{\mathrm{b}}-\mathrm{C}_{\mathrm{b}}$ band vibrational energy level of $\mathrm{Cu}(\mathrm{TMP})$.

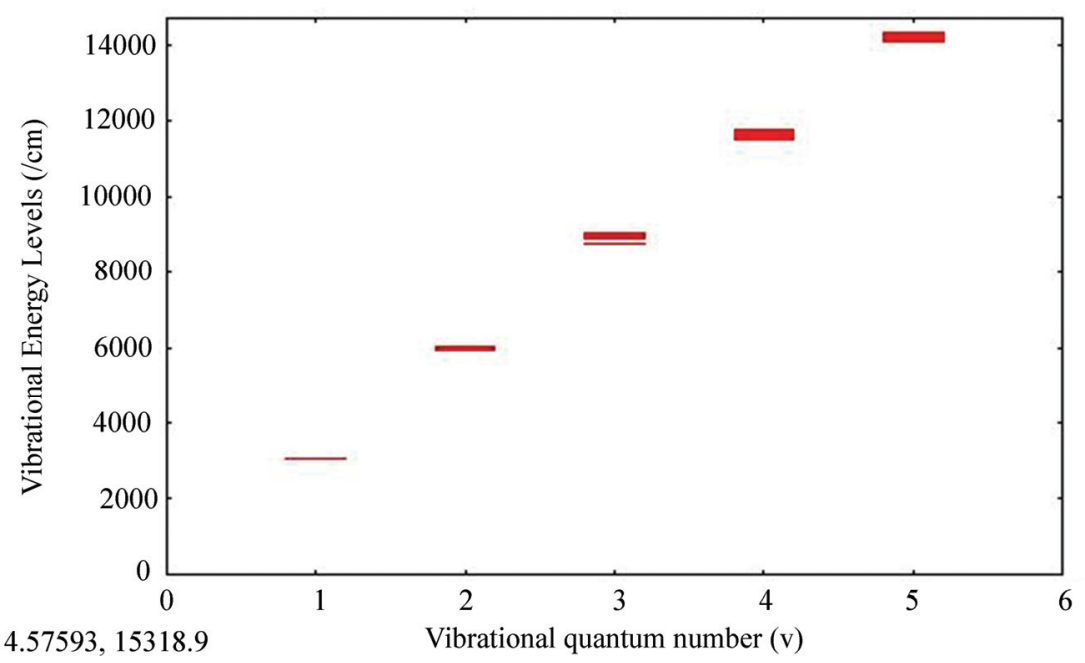

Figure 8. $\mathrm{C}_{\mathrm{m}}-\mathrm{H}$ band vibrational energy level of $\mathrm{Ni}(\mathrm{OEP})-\mathrm{d}_{4}$.

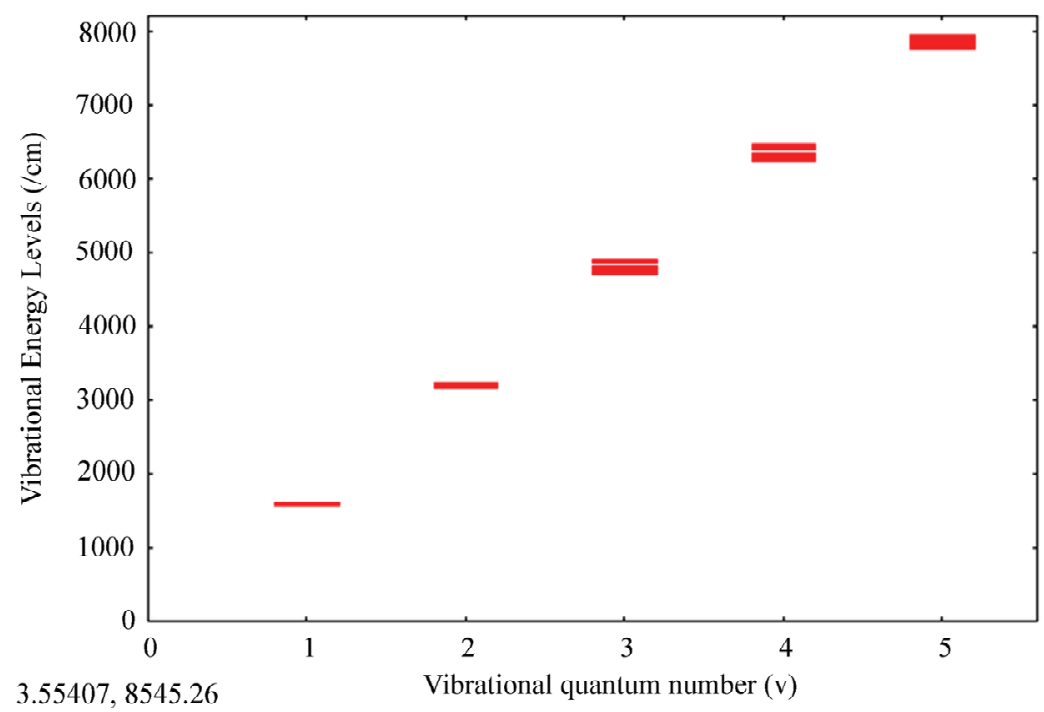

Figure 9. $\mathrm{C}_{\mathrm{b}}-\mathrm{C}_{\mathrm{b}}$ band vibrational energy level of $\mathrm{Ni}(\mathrm{OEP})-\mathrm{d}_{4}$. 


\section{REFERENCES}

[1] Iachello, F. (1981) Algebraic methods for molecular rotation-vibration spectra. Chemical Physics Letters, 78(3), 581-585.

[2] Iachello, F. and Levine, R.D. (1982) Algebraic approach to molecular rotation-vibration spectra. I. Diatomic molecules. Journal of Chemical Physics, 77(6), 3046-3055.

[3] Van Roosmalen, O.S., Dieperink, A.E.L. and Iachello, F. (1982) A dynamic algebra for rotation-vibration spectra of complex molecules. Chemical Physics Letters, 85(1), 32-36.

[4] Van Roosmalen, O.S., Iachello, F., Levine R.D. and Dieperink, A.E.L. (1983) Algebraic approach to molecular rotation-vibration spectra. II. Triatomic molecules. Journal of Chemical Physics, 79(6), 2515-2536.

[5] Sarkar, N.K., Choudhury, J. and Bhattacharjee, R. (2006) An algebraic approach to the study of the vibrational spectra of HCN. Molecular Physics, 104(19), 3051-3055.

[6] Sarkar, N.K., Choudhury, J. and Bhattacharjee, R. (2008) Algebraic approach: Study of vibrational spectra of some linear triatomic molecules. Indian Journal of Physics, 82(6), 767-772

[7] Sarkar, N.K., Choudhury, J., Karumuri, S.R. and Bhattacharjee, R. (2009) A comparative study of the vibrational spectra of OCS and HCP using the Lie algebraic method. European Physical Journal D, 53(2), 163-171.

[8] Sarkar, N.K., Choudhury, J., Karumuri, S.R. and Bhattacharjee, R. (2008) An algebraic approach to the comparative study of the vibrational spectra of monofluoroacetylene (HCCF) and deuterated acetylene (HCCD). Molecular Physics, 106(5), 693-702.

[9] Choudhury, J., Karumuri, S.R., Sarkar, N.K. and Bhattacharjee, R. (2008) Vibrational spectroscopy of $\mathrm{SnBr}_{4}$ and $\mathrm{CCl}_{4}$ using Lie algebraic approach. Pramana Journal of Physics, 71(3), 439-445.

[10] Choudhury, J., Sarkar, N.K. and Bhattacharjee, R. (2008) Algebraic approach to analyze the vibrational spectra of tetrahedral molecules. Indian Journal of Physics, 82(5), 561-565.

[11] Choudhury, J., Karumuri, S.R., Sarkar, N.K. and Bhattacharjee, R. (2009) Vibrational spectroscopy of $\mathrm{CH} / \mathrm{CD}$ stretches in propadiene: An algebraic approach. Chinese Physics Letters, 26(2), 020308.

[12] Karumuri, S.R., Sarkar, N.K., Choudhury, J. and Bhattacharjee, R. (2008) Vibrational spectroscopy of $\mathrm{C}_{m}-\mathrm{H}$, $\mathrm{C}_{b}-\mathrm{C}_{b}$ stretching vibrations of Nickel Metalloporphyrins: An algebraic approach. Molecular Physics, 106(14), 17331738 .

[13] [Karumuri, S.R., Choudhury, J., Sarkar, N.K. and Bhattacharjee, R. (2008) Analysis of resonance raman spectra of Nickel Octaethyl Porphyrin using Lie algebra. Journal of Environmental Research and Development, 3(1), 250-256.

[14] Karumuri, S.R., Sarkar, N.K., Choudhury, J. and Bhattacharjee, R. (2009) Study of vibrational spectra of Nickel Metalloporphyrins: An algebraic approach. Pramana - Journal of Physics, 72(3), 517-525.

[15] Karumuri, S.R., Sarkar, N.K., Choudhury, J. and Bhattacharjee, R. (2009) Vibrational spectroscopy of stretch- ing and bending modes of Nickel Tetra Phenyl Porphyrin: An algebraic approach. Chinese Physics Letters, 26(9), 093301.

[16] Karumuri, S.R., Sarkar, N.K., Choudhury, J. and Bhattacharjee, R. (2009) U(2) algebraic model applied to stretching vibrational spectra of Metalloporphyrins. Journal of Molecular Spectroscopy, 255(2), 183-188.

[17] Karumuri, S.R. and Prasad, A.S.R. (2009) Analysis of vibrational spectra of Copper Octaethyl Porphyrin $[\mathrm{Cu}$ (OEP)] using $\mathrm{U}(2)$ algebraic technique. International Journal of Computational Mathematical Ideas, 1(3), 68.

[18] Karumuri, S.R., Choudhury, J., Sarkar, N.K. and Bhattacharjee, R. (2010) Vibrational spectroscopy of $\mathrm{C}_{m}-\mathrm{C} /$ $\mathrm{C}_{b}-\mathrm{C}_{b}$ stretching vibrations of Copper Tetramesityl Porphyrin $\mathrm{Cu}$ (TMP): An algebraic approach. Pramana Journal of Physics, 74(1), 57-66.

[19] Iachello, F. and Oss, S. (1990) Overtone frequencies and intensities of bent $X Y_{2}$ molecules in the vibron model. Journal of Molecular Spectroscopy, 142(1), 85-107.

[20] Iachello, F., Oss, S. and Lemus, R. (1991) Vibrational spectra of linear triatomic molecules in the vibron model. Journal of Molecular Spectroscopy, 146(1), 56-78.

[21] Iachello, F., Oss, S. and Lemus, R. (1991) Linear four-atomic molecules in the vibron model. Journal of Molecular Spectroscopy, 149(1), 132-151.

[22] Wang, M.S., Ding, S.L., Feng, D.T. and Liu, H.Y. (2002) Lie-algebraic approach to vibrational spectra of a linear symmetrical tetratomic molecule: $\mathrm{C}_{2} \mathrm{H}_{2}$. Physical Review $A, 66,(022506) 1-10$.

[23] Van Roosmalen, O.S., Levine, R.D. and Dieperink, A.E.L. (1983) The geometrical-classical limit of algebraic Hamiltonians for molecular vibrotational spectra. Chemical Physics Letters, 101(6), 512-517.

[24] Benjamin, I., Van Roosmalen, O.S. and Levine, R.D. (1984) A model algebraic Hamiltonian for interacting nonequivalent local modes with application to HCCD and $\mathrm{H}^{12} \mathrm{C}^{13} \mathrm{CD}$. Journal of Chemical Physics, 81(7), 3352-3353.

[25] Van Roosmalen, O.S., Benjamin, I. and Levine, R.D. (1984) A unified algebraic model description for interacting vibrational modes in ABA molecules. Journal of Chemical Physics, 81(12), 5986-5997.

[26] Halonen, L. and Child, M.S. (1983) Model stretching overtone eigenvalues for $\mathrm{SF}_{6}, \mathrm{WF}_{6}$, and $\mathrm{UF}_{6}$. Journal of Chemical Physics, 79(2), 559-570.

[27] Bowman, J.M., Wierzbicki, A. and Zuniga, J. (1988) Exact vibrational energies of non-rotating $\mathrm{H}_{2} \mathrm{O}$ and $\mathrm{D}_{2} \mathrm{O}$ using an accurate ab initio potential. Chemical Physics Letters, 150(3-4), 269-274

[28] Iachello. F and Oss, S. (1991) Model of $n$ coupled anharmonic oscillators and applications to octahedral molecules. Physical Review Letters, 66(23), 2976-2979.

[29] Iachello. F and Oss, S. (1991) Stretching vibrations of benzene in the algebraic model. Chemical Physics Letters, 187(5), 500-505.

[30] Alhassid, Y., Gursey, F. and Iachello, F. (1983) Group theory approach to scattering. Annual Physics (New York), 148(2), 346-380.

[31] Alhassid, Y., Gursey, F. and Iachello, F. (1983) Group theory of the Morse oscillator. Chemical Physics Letters, 99(1), 27-30.

[32] Levine, R.D. (1983) Representation of one-dimensional 
motion in a morse potential by a quadratic Hamiltonian. Chemical Physics Letters, 95(2), 87-90.

[33] Child, M.S. and Halonen, L.O. (1984) Overtone frequencies and intensities in the local mode picture. Advances in Chemical Physics, 57, 1-58.

[34] Li, X.-Y., Czernuszewicz, R.S., Kincaid, J.R., Stein, P. and Spiro, T.G., (1990) Consistent porphyrin force field. 2. Nickel octaethylporphyrin skeletal and substituent mode assignments from nitrogen-15, meso-d4, and methylene-d16 Raman and infrared isotope shift. Journal of Physical Chemistry, 94(1), 47-61.

[35] Kitagawa, T., Abe, M. and Ogoshi, H. (1978) Resonance
Raman spectra of octaethylporphyrinato-Ni(II) and mesodeuterated and $15 \mathrm{~N}$ substituted derivatives. I. Observation and assignments of nonfundamental Raman lines. Journal of Chemical Physics, 69(10), 4516-4525.

[36] Czernuszewicz, R.S., Macor, K.A., Li, X.-Y., Kincaid, J.R. and Spiro, T.G. (1989) Resonance Raman spectroscopy reveals a1u vs. a2u character and pseudo-JahnTeller distortion in radical cations of nickel(II), copper(II), and chloroiron(III) octaethyl- and tetraphenylporphyrins. Journal of the American Chemical Society, 111(11), 3860-3869. 